\title{
HIGH PERFORMANCE LIQUID CHROMATOGRAPHY OF DEXTROMETHORPHAN AND ITS MAIN METABOLITE IN HUMAN URINE
}

Y.H. Noraliza', Z. Mohamed'*, A. Zaini ${ }^{2}$ and C.C. Lang ${ }^{2}$

Departments of 'Pharmacology and ${ }^{2}$ Medicine, Faculty of Medicine, University of Malayo, 50603 Kuala Lumpur, Malaysia.

\begin{abstract}
Dextromethorphan (DM) is O-demethylated to its main metabolite, dextrorphan (DO), following a polymorphic reaction that depends on the isoenzyme, cytochrome P4502D6 (CYP2D6). Traditionally, phenotyping of this isoenzyme utilises debrisoquine, individuals with rapid or normal metabolism of debrisoquine are described as "extensive metabolisers" and those with slower drug metabolism are known as "poor metabolisers". Drug oxidation phenotyping with DM has been found to be in complete concordance with results of phenotyping with debrisoquine.
\end{abstract}

A sensitive High Performance Liquid Chromatography method with both fluorescent and UV detection was developed for the analysis of DM and DO in human urine. Prior to analysis by HPLC, the urine samples were subjected to enzymatic hydrolysis of the dextrorphan glucuronides followed by extraction into chloroform:isopropanol mixture. Standard curves for both compounds were linear over concentrations ranging from 0 to $500 \mathrm{ng} / \mathrm{ml}$ with a mean linear regression value of 0.98 for DM and 0.97 for DO. The intra-assay error was $4.07 \%$ and $7.05 \%$ for DM and DO respectively and the interassay error was $18.16 \%$ and $7.13 \%$ for DM and DO respectively.

Following ingestion of $\mathbf{1 5} \mathrm{mg}$ dextromethorphan hydrobromide, a preliminary oxidation phenotyping was performed on 8 volunteers. The metabolite ratio was calculated as $M R=0-8 \mathrm{hr}$ urinary output of unchanged DM / 0-8 hr urinary output of DO. The total urinary output of DM ranged from 0 to $4.87 \mathrm{mg}$ whereas that of DO ranged from 0.57 to $21.00 \mathrm{mg}$. The MR values were between 0 to 0.220 in 7 of the subjects tested while 1 subject showed a relatively high MR value of 1.376 . This was consistent with the finding that in this same subject the urinary output of DM was the highest, and the output of DO was the lowest among those tested, thus indicating that this subject is possibly a poor metabiliser of DM.

It is concluded that the assay is sensitive for the measurements of levels of DM and DO in human urine and hence will be utilised in a large scale study of the frequency distribution of drug oxidation phenotyping with DM in a Malaysian population. (JUMMEC 1997 2(1):22 - 25)

KEYWORDS: Genetic polymorphism; CYP2D6; dextromethorphan oxidation phenotyping

\section{Introduction}

Variable rates of drug metabolism in man continue to pose one of the biggest hurdles to the effective and safe use of therapeutic agents. The influence of genetic control on hepatic drug metabolism had gained interest since the description of a genetic polymorphism in the capacity to metabolise 4-hydroxylate debrisoquine (1). Two phenotypes were identified; most subjects were extensive metabolisers (EM) whereas a minority of subjects were poor metabolisers (PM) (2). The impairment of debrisoquine 4-hydroxylation is inherited as an autosomal recessive trait $(3,4)$ and is now found to be related to the deficiency of cytochrome P450
2D6 (CYP2D6). CYP2D6 is involved in the stereospecific metabolism of several important groups of drugs, for example, antiarrhythmics like encainide, antidepressants like desipramine $(5,6)$ and neuroleptics like haloperidol $(7,8)$.

About $7 \%$ of Caucasians but only $1 \%$ of Orientals are poor metabolisers (PMs) of debrisoquine (9). This phenomenon of polymorphism has several consequences ranging from rational drug use for the "Corresponding address:

Associate Professor Zahurin Mohamed

Department of Pharmacology

Faculty of Medicine, University of Malaya,

50603 Kuala Lumpur, Malaysia. 
individual in a racially diverse population such as in Malaysia to the development, evaluation and regional as well as world-wide licensing of drugs.

There is a scarcity of information of the prevalence of PMs in this region. Studies will have to be carried out to determine the proportion of subjects genetically deficient in CYP2D6 activity (10). Dextromethorphan is metabolised by CYP2D6 to dextrorphan, its main metabolite. Drug oxidation phenotyping with dextromethorphan is in complete concordance with results of phenotyping with debrisoquine $(11,12)$. Dextromethorphan, a potent cough suppressant found in some over-the-counter cough syrups, has the advantages over debrisoquine in that it is ubiquitously available and lacks of the hypotensive effects of debrisoquine. The aim of this study was to find a suitable method for the detection of dextromethorphan and dextrorphan (Figure I) in human urine and to carry out a preliminary study of CYP2D6 activity in 8 healthy volunteers among the Malaysian population.

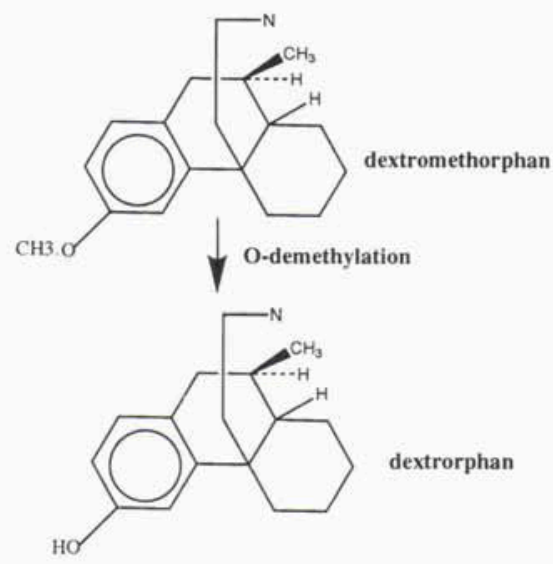

Figure I : The metabolic pathway of the $\mathrm{O}$ demethylation of dextromethorphan to dextrorphan

\section{Material and method}

\section{Analytical Procedures}

Dextromethorphan hydrobromide and dextrorphan, were obtained from Salford Ultrafine Chemicals and Research (Manchester). Rifampicin was obtained from Sigma Chemicals. Dextromethorphan and dextrorphan in urine were assayed by High Performance Liquid Chromatography (HPLC). The HPLC is composed of a LCIOAS pump with RF-IOA fluorescence detector and SPD- IOA detector (Shimadzu Corp. Japan). The columns used were a Cl 8 guard column (Supelco) and an analytical ODS ultrasphere $(4.6 \mathrm{~mm} \times 25 \mathrm{~cm})$ column (Beckman). Extraction methods were modified from a previously described method by Schmidt et al. (II), which, instead of using ether, a mixture of chloroform:2propanol $(85: 15 \mathrm{v} / \mathrm{v})$ was used. In addition, rifampicin was used as an internal standard instead of dimetacrine.
Enzymatic hydrolysis of dextrorphan glucuronides was performed by the addition of $20 \mathrm{ml}$ of B-glucuronides/ sulphatase $(11,13,14)$ and shaken overnight at $37^{\circ} \mathrm{C}$ in a shaking bath for complete conjugation cleavage. I ml of urine was diluted in $\mathrm{I} \mathrm{ml}$ of $0.1 \mathrm{M}$ acetate buffer $\mathrm{pH}$ 5.0 and extracted with $5 \mathrm{ml}$ of the solvent mixture. After 15 seconds of rigorous vortex at speed of 70 and 15 minutes of horizontal shaking, the mixture was centrifuged, $3 \mathrm{ml}$ of the organic phase was transferred into centrifuge tubes, then evaporated off. The residue obtained was dissolved in $100 \mu \mathrm{l}$ of mobile phase. In the case of dextromethorphan analysis, because of its low concentration in some of the urine samples, the residue was dissolved in $50 \mathrm{ul}$ mobile phase (15). The mobile phase was made up of $10 \mathrm{mM}$ potassium phosphate buffer $\mathrm{pH} 4.2$ containing $0.17 \%$ octane sulphonic acid:methanol:acetonitrile $(63: 5: 32 \mathrm{v} / \mathrm{v} / \mathrm{v})$ at a flow rate of $1.2 \mathrm{ml} / \mathrm{min}$. The function of the octane sulphonic acid was to separate the overlapped peaks of dextrorphan from a urine residue. Dextromethorphan and dextrorphan were detected using fluorescence detection at an emission wavelength of $312 \mathrm{~nm}$ and excitation wavelength of $270 \mathrm{~nm}$ (16) while rifampicin was detected using UV detection at $254 \mathrm{~nm}$. Standards for both dextromethorphan and dextrorphan were prepared at concentrations ranging from 0 to $500 \mathrm{ng} /$ $\mathrm{ml}$. Standards were prepared in duplicates. Percentage recovery for both drugs were also performed.

\section{Subjects}

The study was performed in 8 unrelated subjects, 23 to 40 years old. All subjects were examined by a medical doctor to assess the state of their health. Once the subjects were judged as being healthy and not taking other medication, they were given an information sheet which detailed the aim of the study as well as the protocol. All the subjects involved gave their informed consent. The study was approved by the Ethics Committee of the Faculty of Medicine, University of Malaya.

\section{Phenotyping}

Each subject took a tablet of $15 \mathrm{mg}$ dextromethorphan hydrobromide at $2200 \mathrm{~h}$ having emptied their bladder just before swallowing the tablet. A sample of this urine was collected to serve as the individual blank urine. Overnight $8 \mathrm{hr}$ urine was collected by making sure that the subjects emptied their bladder at $0600 \mathrm{~h}$ as their final urine. Subjects then noted the volume of urine voided. The urine samples were handed in the following morning and stored at $-20^{\circ} \mathrm{C}$ until analysis. Subjects were phenotyped using the metabolite ratio (MR) calculated as :

$$
M R=\frac{0.8 \mathrm{~h} \text { urinary output of unchanged dextromethorphan }}{0-8 \mathrm{~h} \text { urinary output of dextrorphan }}
$$




\section{Results}

A method which enabled the detection of both dextromethorphan and dextrorphan in human urine using rifampicin as the internal standard was used. Retention time for dextrorphan was found to be 5.18 $\mathrm{min}$ and dextromethorphan was $15.7 \mathrm{~min}$ while the retention time for the internal standard was found to be between 14.9 to $18.6 \mathrm{~min}$ (Fig.2, Fig. 3). A constant check was carried out to confirm the internal standard peak through the use of extracted blank urine spiked with rifampicin. Standard curves for dextromethorphan and dextrophan were prepared from concentrations ranging from 0 to $500 \mathrm{ng} / \mathrm{ml}$. Standard curves were constructed from the area ratio (measured by the peak area of the dextromethorphan or dextrorphan peak to the peak area of internal standard), plotted against the concentration of these compounds. Linear plots were obtained with a mean $r$ value of 0.98 for dextromethorphan and 0.97 for dextrorphan. Extraction recovery for dextromethorphan was $60.0 \%$ and for dextrorphan it was $75.5 \%$. Interassay error of analysis was $18.16 \%$ and $7.13 \%$ for dextromethorphan and dextrorphan respectively. Intra-assay error for the analysis of dextromethorphan was $4.07 \%$ whilst that of dextrorphan was $7.05 \%$.

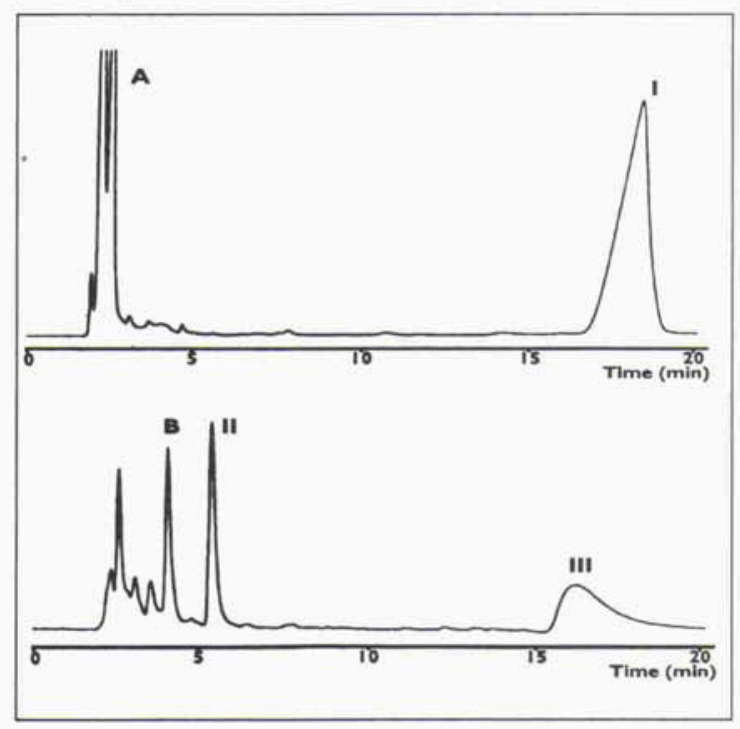

Figure 2. Chromatograms of (A) control urine with internal standard (peak I) and (B) control urine spiked with dextrorphan (peak II) and dextromethorphan (peak III).

Seven out of the eight subjects tested had a metabolite ratio between 0.0003 to 0.2264 (Table I) and were classified as extensive metabolisers (EM). One subject with an MR of I.376 was classified as a poor metaboliser (PM). The mean values of the urinary output of the test drug and its metabolite, as well as the dose recoveries found in EM as compared to PM were vastly different.
Table I. Shows the mean urinary output and recoveries and metabolic ratios of DM and DO in EMs and PM.

\begin{tabular}{lcc}
\hline & $\begin{array}{c}\text { Extensive } \\
\text { Metabolisers }\end{array}$ & $\begin{array}{c}\text { Poor } \\
\text { Metaboliser }\end{array}$ \\
\hline Number of Subjects & 7 & 1 \\
Age (Years) & $25.7 \pm 4.1$ & 24 \\
(Range) & $(24-40)$ & \\
$\begin{array}{l}\text { Dextromethorphan } \\
\text { (DM) output }\left(\mu \text { mol } 8 \mathrm{~h}^{-1}\right)\end{array}$ & $1.63 \pm 1.46$ & 23.95 \\
(Range) & $(0.00-1.31)$ & \\
$\begin{array}{l}\text { Dose recovery as } \\
\text { dextromethorphan }(\%)\end{array}$ & $2.95 \pm 2.64$ & 43.32 \\
(Range) & $(0.00-8.75)$ & \\
$\begin{array}{l}\text { Dextrorphan (DO) } \\
\left.\text { output ( } \mu \text { mol } 8 \mathrm{~h}^{-1}\right)\end{array}$ & $41.90 \pm 14.30$ & 18.40 \\
(Range) & $(22.68-67.70)$ & \\
$\begin{array}{l}\text { Dose recovery as } \\
\text { Dextrorphan (\%) } \\
\text { (Range) }\end{array}$ & $75.80+25.80$ & 33.29 \\
$\begin{array}{l}\text { MR= DM output } \\
\text { DO output }\end{array}$ & $(40.71-122.99)$ & \\
(Range) & $0.0588 \pm 0.060$ & 1.376 \\
\hline
\end{tabular}

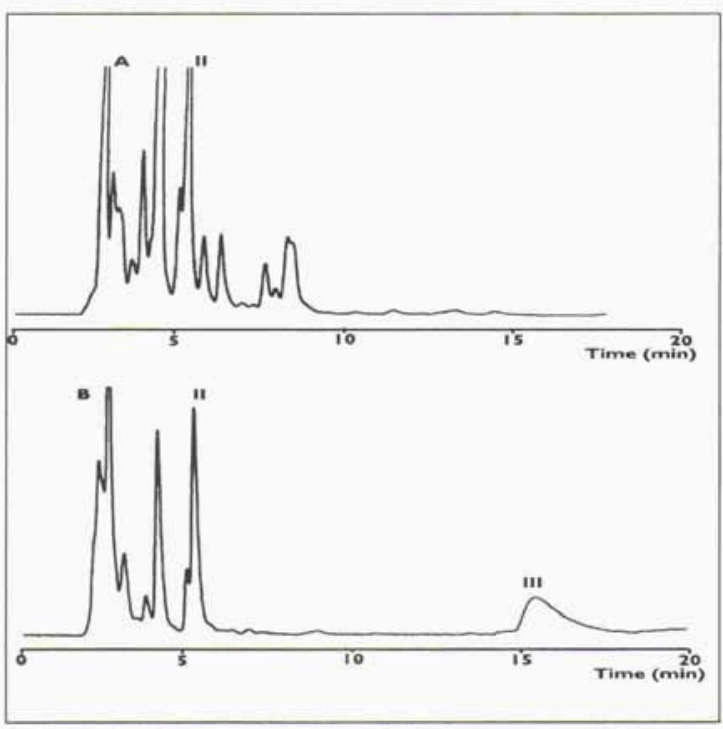

Figure 3. Chromatograms of (A) urine sample from an extensive metaboliser and (B) urine sample from a poor metaboliser. Note the presence of the dextromethorphan peak (peak III) in chromatogram B and the absence of such a peak in chromatogram $A$.

Urinary output of unchanged dextromethorphan was between 0 to $1.31 \mu \mathrm{mol} 8 \mathrm{~h}^{-1}$ in EMs while that of the PM was $23.95 \mu \mathrm{mol} 8 \mathrm{~h}^{-1}$. The dose recovery in urine as unchanged dextromethorphan was between 0.00 to $8.75 \%$ in EMs while that of the PM was $43.32 \%$. In line with the reduced ability of the PMs to metabolise the test drug, urinary output of dextrorphan was between 